\title{
Geïntegreerde seksespecifieke huisartsgeneeskunde in de Nijmeegse huisartsopleiding: competenties, opzet en evaluatie*
}

\author{
P.W. Dielissen, B.J.A.M. Bottema, P. Verdonk, A.L.M. Lagro-Janssen
}

\section{Samenvatting}

Inleiding: Sekse speelt een rol bij medische zorg. In toenemende mate wordt van huisartsen verwacht dat zij rekening houden met contextuele factoren waaronder sekse. In het raamplan van de huisartsopleidingen zijn seksespecifieke competenties beschreven. Om huisartsen in opleiding deze competenties te laten verwerven is onderwijs in seksespecifieke huisartsgeneeskunde noodzakelijk.

Methoden: Er is een curriculum ontwikkeld, bestaande uit vijf modules, waarin de seksespecifieke competenties zijn uitgewerkt. Er worden evidence-based leermethoden gebruikt om aios huisartsgeneeskunde seksespecifiek medisch handelen te leren (interactief, praktijkgericht, reflectief). Het seksespecifieke curriculum is een geïntegreerd onderdeel van de huisartsopleiding. Tussen 2005-2008 is na elke module de aios gevraagd een evaluatieformulier in te vullen met de bedoeling het onderwijs te evalueren en leerpunten te inventariseren.

Resultaten: De modules van het betreffende onderwijsprogramma zijn verdeeld over de driejarige huisartsopleiding. In het onderwijs worden seksespecifieke onderwerpen behandeld met een hoge huisartsgeneeskundige relevantie zoals de arts-patiënt communicatie, hart- en vaatziekten en depressie. De evaluatie van het onderwijs is overwegend positief. De geformuleerde leerpunten van de aios sluiten aan bij de competenties van het seksespecifieke onderwijsprogramma.

Discussie en conclusie: Met succes is een seksespecifiek onderwijsprogramma geïmplementeerd in de Nijmeegse huisartsopleiding. De evaluatie laat zien dat het onderwijs in seksespecifieke huisartsgeneeskunde positief wordt gewaardeerd. Daarnaast draagt het onderwijs bij aan een besef van de invloed van de factor sekse in de dagelijkse medische praktijk. De modulaire opbouw en de competentiegerichte onderwijsmethoden maken het geschikt voor andere huisartsopleidingen. (Dielissen PW, Bottema BJAM, Verdonk P, Lagro-Janssen ALM. Geïntegreerde seksespecifieke huisartsgeneeskunde in de Nijmeegse huisartsopleiding: competenties, opzet en evaluatie. Tijdschrift voor Medisch Onderwijs 2010(29);3:200-209.)

\section{Inleiding}

Seksespecifieke geneeskunde bestudeert de invloed van de sekse van de patiënt(e) en de dokter in ziekte en gezondheid. ${ }^{1}$ Met sekse (het equivalent van het Engelse 'gender') worden niet alleen biologische, maar met name de psychologische en sociaal-culturele kenmerken van mannen en vrouwen bedoeld. Seksespecifieke huisartsgeneeskunde stelt zich als doel handvatten te reiken aan huisartsen met betrekking tot het gebruik van de factor

\footnotetext{
* Dit artikel verscheen eerder onder de oorspronkelijke titel: Patrick W Dielissen, Ben JAM Bottema, Petra Verdonk and Toine L.M. Lagro-Janssen. Incorporating and evaluating an integrated gender-specific medicine curriculum: a survey study in Dutch GP training. BMC Med Educ 2009;9(1):58.
} 
sekse in de dagelijkse praktijk. Hiermee wordt beoogd gelijkwaardige zorg te bieden aan vrouwen en mannen. ${ }^{2-3}$ Van diverse gezondheidsproblemen zijn sekseaspecten of sekseverschillen bekend. ${ }^{4-8}$ Zo speelt sekse bijvoorbeeld een rol in de presentatie van klachten bij chronisch obstructieve longziekten (COPD); vrouwen met COPD hebben vaker angst- en stemmingsklachten dan mannen met dezelfde aandoening. ${ }^{4} 9$ Zowel bij mannen als vrouwen duidt een kenmerkende pijn op de borst bij inspanning op angina pectoris. Echter, deze typische inspanningsgebonden pijn op de borst met eventuele uitstralende pijn komt bij vrouwen minder vaak voor, vooral op oudere leeftijd en/of in relatie met diabetes mellitus. ${ }^{10-11}$ Ook kunnen verschillen tussen mannen en vrouwen in levenservaringen (seksueel geweld, maatschappelijke positie) belangrijk zijn voor de inhoud van de medische zorg. ${ }^{12-13}$

De integratie van dergelijke kennis over sekse blijkt in de medische opleidingen achter te blijven. ${ }^{14-16}$ Onvoldoende steun op diverse organisatorische niveaus in medische faculteiten, gebrekkige integratie in het curriculum zoals het geval is bij keuzeonderwijs of facultatief onderwijs, en het ontbreken van toetsing dragen daaraan bij. Toch zijn er de afgelopen jaren ook positieve ontwikkelingen geweest zoals vermelding van seksespecifieke competenties voor de huisartsopleiding, de screening van bestaand onderwijs op sekseaspecten in het basiscurriculum geneeskunde en in de vervolgopleidingen bij alle faculteiten en advisering voor aanpassing of aanvullingen van het onderwijs. ${ }^{17-21}$

Professionals op het gebied van de seksespecifieke huisartsgeneeskunde hebben zich de afgelopen jaren intensief bezig gehouden met de opleiding van docenten, de ontwikkeling van onderwijsmateriaal en de ontwikkeling van onderwijsprogramma's seksespecifieke geneeskunde. ${ }^{22-24}$ Voort- schrijdend inzicht in de faciliterende en belemmerende factoren van het seksespecifieke onderwijs heeft een belangrijke bijdrage geleverd aan de huidige ontwikkeling op dit gebied. ${ }^{17}$ 25-26 Zo blijkt de overdracht van seksespecifieke kennis alleen niet voldoende te zijn om de factor sekse te integreren in het medisch handelen van de dokter. ${ }^{27-28} \mathrm{Er}$ is ruimte en tijd nodig voor het zichtbaar maken van vaak onbewuste seksespecifieke opvattingen en stereotype beeldvorming. Het verwerven van inzicht in bijvoorbeeld de eigen seksesocialisatie op de medische besluitvorming vraagt een langere looptijd van het onderwijs. Om tot het gewenste professionele gedrag te komen is geïntegreerd en klinischgeoriënteerd onderwijs meer succesvol dan facultatief of éénmalig blokonderwijs. ${ }^{29-30}$ Tot slot is naast docentprofessionalisering niet alleen een goede inbedding en organisatie van het onderwijs in de huisartsopleiding gewenst maar ook een breed gedragen verantwoordelijkheid binnen het instituut voor het seksespecifieke onderwijs. ${ }^{17} 2031-32$

Wij ontwikkelden en evalueerden een geïntegreerd onderwijsprogramma 'Seksespecifieke huisartsgeneeskunde' om huisartsen in opleiding (aios) kennis te laten maken met en bewust te maken van de manier waarop sekse een rol speelt in de dagelijkse medische praktijk. Dit streven is overeenkomstig de consensusverklaringen van internationale gezondheidsinstellingen die het belang benadrukken van hulpverlening waarin aandacht is voor de factor sekse. ${ }^{33-34}$

In dit artikel beschrijven we de opzet en de evaluatie van het geïntegreerde seksespecifieke curriculum in de Nijmeegse huisartsopleiding. Het is het tweede artikel van drie waarin het effect gemeten wordt van seksespecifiek onderwijs aan huisartsen in opleiding. ${ }^{18}$ 


\section{Methoden}

\section{De taakgroep en de competenties}

Het onderwijsprogramma Seksespecifieke huisartsgeneeskunde is ontwikkeld door een taakgroep. De taakgroep bestond uit vier huisartsen met expertise op het gebied van seksespecifieke geneeskunde en huisartsgeneeskunde. Allen waren werkzaam bij de Vervolgopleiding tot Huisarts van het UMC St Radboud en bij de afdeling Huisartsgeneeskunde (tegenwoordig afdeling Eerstelijnsgeneeskunde). De eerste stap was een selectie van de onderwerpen van het onderwijsprogramma. De taakgroep stelde zichzelf de volgende vragen bij de keuze van de onderwerpen:

- Is het onderwerp relevant voor de huisarts en ziet de huisarts de problematiek regelmatig op het spreekuur?

- Zijn er seksespecifieke aspecten of sekseverschillen bekend over het onderwerp die van belang zijn voor de praktijk?

- Is er voldoende wetenschappelijke basis voor deze seksespecifieke aspecten of sekseverschillen?

De volgende onderwerpen werden gekozen: socialisatie, arts-patiënt communicatie, hart- en vaatziekten, depressie/angststoornissen, urine-incontinentie, verslaving aan alcohol of benzodiazepinen, huiselijk en seksueel geweld. De tweede stap bestond uit de beschrijving van de competenties van de modules (zie Tabel 1). Vervolgens werden aan de seksespecifieke competenties onderwijsactiviteiten gekoppeld om tot een nieuwe module van het onderwijsprogramma te komen. Het onderwijsprogramma richt zich op drie competenties; na de driejarige huisartsopleiding is de aios:

1. zich bewust van sekseaspecten en sekseverschillen in ziekte en gezondheid en heeft inzicht verworven in de wijze waarop de factor sekse het hulpverleningsproces kan beïnvloeden,
2. in staat sekseaspecten en sekseverschillen toe te passen in de epidemiologie, presentatie, diagnostiek en behandeling van huisartsgeneeskundige gezondheidsproblemen,

3. in staat om in de arts-patiënt communicatie en in de arts-patiënt relatie rekening te houden met seksespecifieke aspecten.

\section{Leervisie en onderwijsactiviteiten}

Het leren en opleiden in de huisartsgeneeskunde vindt hoofdzakelijk plaats in de context van de dagelijkse praktijk. Dat wordt ondersteund met theoretisch onderwijs tijdens terugkomdagen. Het leerproces wordt gezien als een cyclus die start bij een waarneming of ervaring van de aios. ${ }^{35}$ De pijlers van dit leerproces zijn: ervaren, reflecteren, objectiveren, toepassen en evalueren. ${ }^{21}$ Leerdoelen worden omschreven als competenties met als doel de integratie van het geleerde in waarneembaar gedrag dat past bij de beroepssituatie. ${ }^{29-30} 36$ In de opzet en de ontwikkeling van het onderwijsprogramma Seksespecifieke huisartsgeneeskunde is zoveel mogelijk volgens deze visie gewerkt.

Specifiek voor het onderwijsprogramma Seksespecifieke huisartsgeneeskunde betekent dit dat docenten de aios in het onderwijs motiveren allereerst na te denken over de factor sekse tijdens verschillende momenten in het zorgcontact met de patiënt (ervaringen, waarnemingen). Voorwaarde is dat de aios termen als sekse/ gender, socialisatie en stereotypen begrijpt en deze weet te herkennen in het medisch handelen (reflecteren). De spreiding over langere tijd van het seksespecifieke curriculum biedt ruimte bij het opdoen van nieuwe ervaringen (toepassen). Herhaalde uitleg over wat seksespecifieke hulpverlening inhoudt en over de manier waarop de aios dat in de praktijk vorm kan geven, staat daar borg voor. 


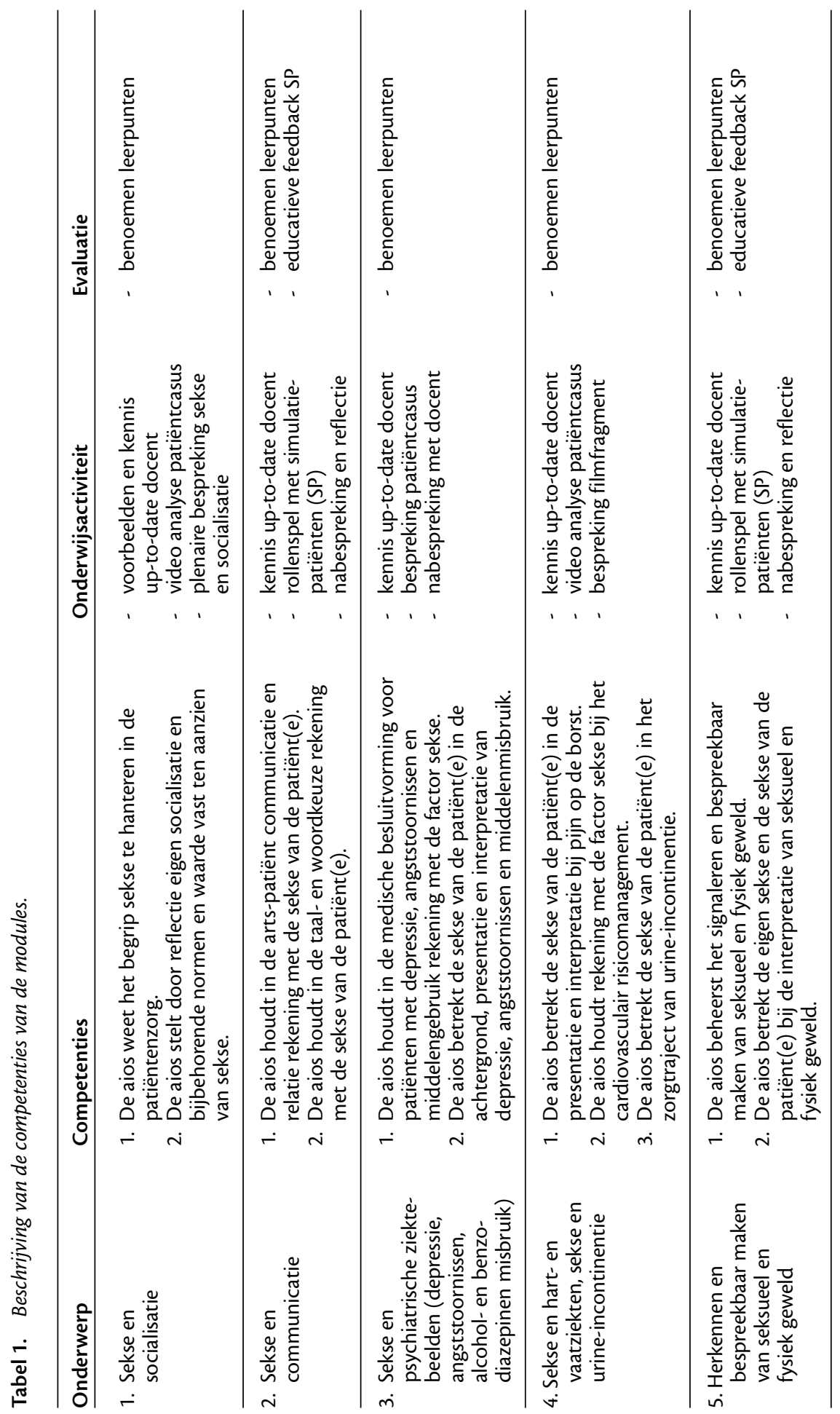


Bewustwording en reflectie op de eigen attitude is een belangrijk onderdeel van adequate seksespecifieke hulpverlening en van de professionaliteit van elke huisarts. De eigen attitude ten aanzien van sekse en de persoonlijke ervaringen ten aanzien van sekserollen kleuren vaak het oordeel over en de waardering van klachten en problemen. ${ }^{36-37}$ Kennis over eigen socialisatie als man of vrouw is dan ook een kernonderdeel van het seksespecifieke curriculum. In het onderwijs wordt geprobeerd na te gaan wat aios doen of nalaten te doen met sekse en sekserollen in de praktijk. Ogenschijnlijke vanzelfsprekendheden, waarden en normen worden voor het voetlicht gebracht.

\section{Opzet}

Het onderwijsprogramma Seksespecifieke huisartsgeneeskunde bestaat uit vijf modules van elk drie uur. In de eerste module worden de basisbegrippen besproken en in de overige vier worden klinische onderwerpen uit de huisartsgeneeskunde behandeld. De onderwijskundige opzet is voor elke module min of meer dezelfde: een introductie van het onderwerp, een ice-breaker, reflectie op eigen handelen, een interactieve werkvorm en een plenaire afsluiting. In de module wordt een overzicht gegeven van de bekende wetenschappelijke kennis over het onderwerp.

Tijdens het onderwijs wordt er gewerkt in groepen van 10 tot 15 aios die veelal bekend zijn met elkaar; er worden afwisselende werkmethoden gebruik zoals videoconsultaties, casuïstiek en rollenspel met simulatiepatiënten. Er is digitale literatuur beschikbaar als voorbereiding op het onderwijs of als verdieping van het onderwerp. Er wordt gebruik gemaakt van variatie in de groepsamenstelling bij de uitvoering van onderwijsactiviteiten (tweetallen, plenair).

\section{Inhoud van het onderwijsprogramma}

De inhoud van de vijf modules wordt hier kort beschreven (zie ook Tabel 1). De vijf modules zijn verdeeld over de driejarige huisartsopleiding.

In de introductiemodule sekse en socialisatie worden de begrippen sekse, gender, sekserollen en socialisatie besproken aan de hand van de eigen socialisatie als man of vrouw. Ook wordt de invloed hiervan besproken op ziekte en gezondheid met aandacht voor sekseverschillen in communicatie, klachtenpresentatie, epidemiologie, beleving en behandeling.

Module twee, sekse en communicatie, richt zich specifiek op sekseverschillen in de communicatie tussen arts en patiënt(e). Dit is met name relevant voor seksespecifieke aandoeningen en bij psychosociale problemen. Sekseaspecten die de communicatie kunnen bevorderen en die de communicatie kunnen belemmeren worden toegelicht.

Module drie bestaat uit twee onderdelen: (a) sekse en depressie en angststoornissen en (b) sekse en misbruik van alcohol en benzodiazepinen. Seksespecifieke aspecten worden besproken evenals een seksespecifieke benadering van de behandeling. Bij alcoholgebruik en -problematiek komt bijvoorbeeld aan de orde dat sekseverschillen tot uiting komen in een grotere biologische kwetsbaarheid van vrouwen voor alcohol en de minder strenge maatschappelijke normen met betrekking tot drinken voor mannen.

In module vier komen de sekseverschillen in hart-en vaatziekten (HVZ), onder andere de presentatie ervan, en urine-incontinentie aan bod. Traditionele risicofactoren kunnen seksespecifieke aspecten hebben. Vrouwen met diabetes mellitus hebben bijvoorbeeld een hoger risico op HVZ dan mannen met diabetes mellitus. Maar ook bij preventie komen specifieke problemen voor, bijvoorbeeld door een vroege meno- 
pauze of het polycysteusovariumsyndroom. Er zijn sekseverschillen bij urine-incontinentie in de epidemiologie, in het ervaren van hinder en bij hulpzoekgedrag. Handvatten voor seksespecifieke hulpverlening voor de vaak oudere groep met ongewild urineverlies worden besproken.

In de laatste en vijfde module, herkenning van de signalen en het bespreekbaar maken van seksueel en fysiek geweld, wordt aandacht besteed aan een veelvoorkomend, vaak ondergediagnosticeerd en beladen onderwerp. Wanneer moet je er naar vragen? Hoe moet je er naar vragen? Sekseaspecten ten aanzien van de motivatie en achtergronden van seksueel en fysiek geweld worden besproken, evenals de manier waarop mannelijke en vrouwelijke huisartsen verschillen in visie en aanpak van huiselijk geweld.

\section{Evaluatie}

$\mathrm{Na}$ iedere module is in de periode 20052008 aan alle aios gevraagd een evaluatieformulier in te vullen met aanvankelijk zes items (2005) en vanaf 2007 acht items. Elk item richtte zich op de evaluatie van een onderdeel van het onderwijs: relevantie voor de praktijk, toepasbaarheid voor de praktijk, gebruikte werkvormen, didactische vaardigheden van de docent en het onderwijsmateriaal. De aios is ook gevraagd twee leerpunten op te schrijven. Het invullen van het evaluatieformulier gebeurde op vrijwillige basis. Voor het scoren van de items maakten we gebruik van een vijfpunts Likertschaal waarbij 1 'volledig oneens' en 5 'volledig eens' met het item betekende.

De verkregen data werden ingevoerd en geanalyseerd in SSPS 16.0. De antwoorden 1,2 of 3 hebben we gecodeerd als een negatieve beoordeling van het onderwijs, de antwoorden 4 en 5 als een positieve beoordeling. De leerpunten werden gecodeerd aan de hand van de drie competenties van het onderwijsprogramma. Gerapporteerd werd hoe vaak de aios leerpunten formuleerden die overeenkwamen met de competenties. Verschillen tussen de aios werden getest met de Chi-kwadraat toets. Bij de beoordeling van de verschillen werd het 5\%-significantieniveau gebruikt.

\section{Resultaten}

In de periode februari 2005 tot september 2008 werden in totaal 442 evaluatieformulieren verzameld; een responspercentage van $49 \%$. Van deze 442 evaluatieformulieren was $32.8 \%$ ingevuld door mannelijke aios $(n=145)$ en $64.7 \%$ door vrouwelijke aios $(n=286)$. Op 11 evaluatieformulieren was het geslacht niet vermeld (2.5\%).

De aios vonden seksespecifieke huisartsgeneeskunde een relevant onderwerp voor hun opleiding (mannen $79.5 \%$ versus vrouwen $87.2 \%$; $\mathrm{X}^{2}=2.42$; ns). De gebruikte voorbeelden in het onderwijs en de aangeboden seksespecifieke kennis werden als goed bruikbaar ervaren voor hun eigen dagelijkse praktijk (mannen $82.1 \%$ versus vrouwen $89.6 \%, \mathrm{X}^{2}=2.72$; ns). Een ruime meerderheid van de aios $(80 \%)$ had een positief oordeel over de werkmethode, de opzet van het programma en over de wijze waarop de docent het onderwerp voor het voetlicht bracht. We vonden geen significante verschillen in de beoordeling of waardering van het onderwijs tussen mannelijke en vrouwelijke aios maar vrouwelijke aios scoorden wel consequent hoger op alle items van de evaluatie.

De aios noteerden 743 leerpunten op de 442 door ons ontvangen evaluatieformulieren. Er waren drie uitgesproken thema's in de leerpunten die overeenkwamen met de kerncompetenties:

1. Sekse als factor in ziekte en gezondheid.

2. Sekseverschillen in de ontvangen medische zorg (gender bias).

3. De invloed van de factor sekse in de artspatiënt communicatie. 
Veel leerpunten betroffen sekseverschillen in het diagnostisch proces of in de behandeling (mannen 39\% versus vrouwen 41\%) zoals in de klachtenpresentatie. De leerpunten over sekseverschillen in de ontvangen medische zorg gingen bijvoorbeeld over ervaren belemmeringen bij het stellen van intieme vragen aan personen van het andere geslacht. Mannelijke aios noemden dit thema even vaak als vrouwelijke aios (34\% versus 31\%). Het laatste thema, sekse en communicatie in de artspatiënt relatie, werd ook even vaak door mannelijke en vrouwelijke aios genoemd als leerpunt (27.1\% versus $27.3 \%$ ). Binnen dit thema werden voorbeelden gegeven zoals het omgaan met statusverschillen in de relatie met de patiënt(e) en het sekseverschil in perceptie van de zorgvraag.

In de evaluatieformulieren van zowel mannelijke als vrouwelijke aios werd bij tijd en wijlen ook kritiek geleverd op het onderwijsprogramma of werd weerstand geuit tegen het onderwijs. Zo zagen we opmerkingen van aios die vonden dat in het seksespecifieke onderwijs te eenzijdig de ongelijke of ongelijkwaardige zorg voor vrouwen werd neergezet. Enkele andere negatieve beoordelingen op evaluatieformulieren bestonden uit simplificaties, bagatellisatie of ontkenningen van de relevantie van de factor sekse voor de huisartsgeneeskunde.

\section{Discussie}

In dit artikel hebben we het onderwijsprogramma Seksespecifieke huisartsgeneeskunde beschreven dat geïntegreerd is in het curriculum van de Nijmeegse huisartsopleiding. Zowel mannelijke als vrouwelijke aios beoordelen het onderwijsprogramma overwegend positief op zowel de inhoud, de vorm als de relevantie voor de praktijk.

Naar ons beste weten is dit het eerste geïntegreerde en geëvalueerde onderwijs- programma seksespecifieke geneeskunde in een vervolgopleiding. Voorgaand onderzoek over medisch onderwijs en seksespecifieke geneeskunde beperkte zich in de regel tot het beschrijven van seksespecifieke competenties en inhoudelijke aanbevelingen voor het onderwijs ${ }^{838}$ of de mate waarin medische opleidingen aandacht besteden aan seksespecifiek onderwijs. ${ }^{26} 3239$ Enkele evaluatieve studies zijn ons bekend waarin daadwerkelijk het effect van blok- of keuzeonderwijs seksespecifieke geneeskunde wordt beschreven. 14-15 3240 Wij hebben met de ontwikkeling en implementatie van dit onderwijsprogramma Seksespecifieke huisartsgeneeskunde een belangrijke stap voorwaarts gezet in de integratie van een belangrijke sociale determinant van ziekte en gezondheid.

Voor de ontwikkeling en uitvoering hebben we intensief gebruik gemaakt van eigen onderzoek en lering getrokken uit lessen van ander onderzoek. ${ }^{15} 32$ 41-44 Naar onze mening zijn er enkele pijlers waarop dit succes steunt. De eerste is dat het een onderdeel is van het verplichte onderwijs dat de eindtermen bestrijkt waaraan elke aios moet voldoen. De tweede is de langere looptijd met gelegenheid voor ervaren, herhalen en groeien. Dat is een voorwaarde om sekse of andere sociale determinanten van ziekte te kunnen leren herkennen. ${ }^{45}$ En als laatste de onderwerpen in het onderwijs, die zijn gekozen vanwege hun hoge huisartsgeneeskundige relevantie waardoor oefensituaties in de praktijk van de aios zich gemakkelijk voordoen.

De evaluatie kent ook enkele beperkingen. Het responspercentage is met bijna 50\% niet hoog en het is niet denkbeeldig dat dit de uitslag van de evaluatie heeft beïnvloed. Het oordeel van de non-respondenten weten we niet. We hebben geen aanwijzingen dat non-responders in grote getale het onderwijs minder positief zouden be- 
oordelen. Het stelselmatig evalueren is zowel voor de docent als voor de aios mogelijk niet altijd prioriteit geweest. De vele evaluatieve momenten in de huisartsopleiding kunnen bijdragen aan een gevoel van verzadiging voor evaluaties bij de aios. De score met meer dan 400 evaluatieformulieren van de verschillende modules, verspreid over drie jaar, geven ons het vertrouwen dat de uitkomsten voldoende representatief zijn. ${ }^{46}$ Een tweede beperking is de voorspellende waarde van een positieve evaluatie van het onderwijs voor het daadwerkelijke seksespecifieke handelen van de aios in de praktijk. Wij hebben geen informatie over het daadwerkelijke spreekuurgedrag in de praktijk. Een derde beperking die we willen noemen is dat aios die het basiscurriculum in Nijmegen hebben gevolgd al eerder kennis gemaakt hebben met seksespecifieke geneeskunde. Dit zou de resultaten mogelijk hebben kunnen beïnvloeden.

Nu seksespecifieke huisartsgeneeskunde een geïntegreerd onderdeel is van de Nijmeegse huisartsopleiding willen we ons vizier richten op verdere implementatie van het onderwerp sekse. Aios leren vooral in de praktijk van de opleider en huisartsopleiders spelen een belangrijke rol in de begeleiding van het leerproces van de aios waarbij zij als rolmodel fungeren. ${ }^{4-48} \mathrm{Het}$ is dan ook van belang de huisartsopleiders seksespecifieke huisartsgeneeskunde aan te bieden. Voor verdere implementatie in de huisartsopleiding is ook de ontwikkeling van toetsing van belang. 'Assessment drives learning'. ${ }^{49}$ Toetsing levert bruikbare informatie op over de beheersingsgraad van een bepaald onderwerp en kan nieuwe ervaringen en waarnemingen voeden. Bijvoorbeeld toetsing van seksespecifieke kennis in de Landelijke Huisartsgeneeskundige Kennistoets en toetsing van seksespecifieke consultatievaardigheden in de arts-patiënt communicatie.

\section{Conclusie}

Onderwijs in seksespecifieke huisartsgeneeskunde in de vervolgopleiding tot huisarts is toepasbaar en uitvoerbaar in modulaire vorm. Huisartsen in opleiding beoordelen het onderwijs overwegend positief. Het onderwijs draagt bij aan het bewustzijn van de factor sekse in ziekte en gezondheid.

\section{Literatuur}

1. Lagro-Janssen AL, Verdonk P. Seksespecifieke huisartsgeneeskunde. Practicum huisartsgeneeskunde. Maarssen: 2007. [Gender-specific family medicine. Family medicine lab. Maarssen: 2007].

2. Hamberg K. Gender bias in medicine. Womens Health (Lond Engl) 2008; 4(3):237-243.

3. Miers M. Developing an understanding of gender sensitive care: exploring concepts and knowledge. J Adv Nurs 2002;40(1):69-77.

4. Han MK, Postma D, Mannino D et al. Gender and COPD: Why it Matters. Am J Respir Crit Care Med 2007;176(12):1179-84.

5. Lagro-Janssen T, Lo FoWong S, van den Muijsenbergh $\mathrm{M}$. The importance of gender in health problems. Eur J Gen Pract 2008;14 Suppl 1:33-37.

6. Legato MJ, Gelzer A, Goland R et al. Gender-specific care of the patient with diabetes: review and recommendations. Gend Med 2006;3(2):131-158.

7. Stoverinck MJ, Lagro-Janssen AL, Weel CV. Sex differences in health problems, diagnostic testing, and referral in primary care. J Fam Pract 1996; 43(6):567-576.

8. Wong T, Singh A, Mann J, Hansen L, McMahon S. Gender Differences in Bacterial STIs in Canada. BMC Womens Health 2004;4 Suppl 1:S26.

9. Chapman KR, Tashkin DP, Pye DJ. Gender bias in the diagnosis of COPD. Chest 2001;119(6):1691-1695.

10. Canto JG, Goldberg RJ, Hand MM et al. Symptom presentation of women with acute coronary syndromes: myth vs reality. Arch Intern Med 2007; 167(22):2405-2413.

11. Lagro-Janssen AL, van Heugten PW, Vogels EA. Angina pectoris en myocardinfarct: verschillen tussen mannen en vrouwen in risicoprofiel en prognose en in verwijzing door de huisarts. Ned Tijdschr Geneeskd 2000;144(11):518-522. [Angina pectoris and myocardial infarction: sex differences in risk profile, prognosis and referral by family physician. Dutch Medical Jounal 2000;144(11): 518-522].

12. Bonhomme J. Men's Health: Key to Healthier Women, Childeren, and Communities. Am J Men Health 2007;1(4):335-338. 
13. Lo Fo Wong SH, Lagro-Janssen AL. Mishandeling van vrouwen binnen de patiëntrelatie: signalering in de medische praktijk. Ned Tijdschr Geneeskd 2005;149(1):6-9. [Intimate partner abuse of women: identification of victims in medical practice. Dutch Medical Journal 2005;149(1):6-9].

14. Henrich JB, Viscoli CM. What do medical schools teach about women's health and gender differences? Acad Med 2006;81(5):476-482.

15. Keitt SK, Wagner C, Tong C, Marts SA. Positioning women's health curricula in US medical schools. Med Gen Med 2003;5(2):40.

16. Verdonk P, Mans LJL, Lagro-Janssen AL. How is Gender integrated in the Curricula of Dutch Medical School? A quick-scan on gender issues as an instrument for change. Gender and Education 2006;18(4):399-412.

17. Celik HH, Klinge II, Weijden TT, Widdershoven GG, Lagro-Janssen TA. Gender sensitivity among general practitioners: results of a training programme. BMC Med Educ 2008;8:36.

18. Dielissen PW, Bottema BJ, Verdonk P, LagroJanssen TL. Incorporating and evaluating an integrated gender-specific medicine curriculum: a survey study in Dutch GP Training. BMC Med Educ 2009;9(1):58.

19. Dijkstra AF, Verdonk P, Lagro-Janssen AL. Gender bias in medical textbooks: examples from coronary heart disease, depression, alcohol abuse and pharmacology. Med Educ 2008;42(10):1021-1028.

20. Verdonk P, Mans LJ, Lagro-Janssen AL. Integrating gender into a basic medical curriculum. Med Educ 2005;39(11):1118-1125.

21. van Berkestijn LGM. Competentieprofiel van de huisarts. Project Vernieuwing Huisartsopleiding. Utrecht; 2005. [Competency profile for general practitioners. Project on Innovation of Postgraduate Training in Family Medicine. Utrecht; 2005].

22. Hatala R, Case SM. Examining the influence of gender on medical students' decision making. J Womens Health Gend Based Med 2000;9(6):617-623.

23. Lagro-Janssen AL.Sex, gender en gezondheid; ontwikkelingen in het wetenschappelijk onderzoek. Ned Tijdschr Geneeskd 2007;151(6):374-378. [Sex, gender and health: developments in scientific research. Dutch Medical Journal 2007;151(6)374-378].

24. Phillips SP. Measuring the health effects of gender. J Epidemiol Community Health 2008;62(4): 368-371.

25. Risberg G, Johansson EE, Westman G, Hamberg K. Attitudes toward and experiences of gender issues among physician teachers: a survey study conducted at a university teaching hospital in Sweden. BMC Med Educ 2008;8:10.

26. Verdonk P, Mans LJL, Lagro-Janssen AL. How is Gender integrated in the Curricula of Dutch Medical Schools? A quick-scan on gender issues as an instrument for change. Gender and Education 2006;18(4):399-412.
27. Pursley HG, Kwolek DS, Griffith CH, Wilson JF. Women's health issues and residents' knowledge. J Ky Med Assoc 2002;100(6):238-244.

28. Spencer AL, Bost JE, McNeil M. Do Women's Health Internal Medicine Residency Tracks Make a Difference? J Womens Health 2007;16(7):1219-1223.

29. Boonyasai RT, Windish DM, Chakraborti C, Feldman LS, Rubin HR, Bass EB. Effectiveness of teaching quality improvement to clinicians: a systematic review. JAMA 2007;298(9):1023-1037.

30. Khan KS, Coomarasamy A. A hierarchy of effective teaching and learning to acquire competence in evidenced-based medicine. BMC Med Educ 2006; 6:59.

31. Hammarstrom A. The integration of gender in medical research and education-obstacles and possibilities from a Nordic perspective. Women Health 2003;37(4):121-133.

32. Henrich JB. Women's health education initiatives: why have they stalled? Acad Med 2004;79(4):283288.

33. Report to AFMC Board of Directors from Special Resource Committee on Gender and Equity; 2006.

34. Lent B, Cohen M, Dunn S, Levitt CA. Promoting gender equity in family medicine. Can Fam Physician 2007;53(9):1415-1418.

35. Projectgroep Implementatie Raamplan. Handreiking voor een opleidingsplan (HOP). Project Vernieuwing Huisartsopleiding. www.pvhuisartsopleiding.nl. Utrecht; 2006. [Project Group for the Implementation of the Blueprint. Suggestions for a training programme (HOP). Project on Innovation of Postgraduate Training in Family Medicine. Utrecht 2006].

36. Mann K, Gordon J, Macleod A. Reflection and reflective practice in health professions education: a systematic review. Adv Health Sci Educ Theory Pract Epub: 2007.

37. Branch WT, Jr., Paranjape A. Feedback and reflection: teaching methods for clinical settings. Acad Med 2002;77(12 Pt 1):1185-1188.

38. Doyal L. Sex, gender, and health: the need for a new approach. BMJ 2001; 323(7320):1061-1063.

39. Wayne DB, DaRosa DA. Evaluating and enhancing a women's health curriculum in an internal medicine residency program. J Gen Intern Med 2004;19(7):754-759.

40. Nicolette J, Jacobs MB. Integration of women's health into an internal medicine core curriculum for medical students. Acad Med 2000;75(11): 1061-1065.

41. Celik HH, Lagro-Janssen AL, Klinge I, van der Weijden T, Widdershoven G. Maintaining Gender Sensitivity in the Family Practice: Facilitators and Barriers. Journal of Evaluation in Clinical Practice 2009;15(6):1220-1225.

42. Lent B, Bishop JE. Sense and sensitivity: developing a gender issues perspective in medical education. J Womens Health 1998;7(3):339-342. 
43. Phillips SP, Ferguson KE. Do students' attitudes toward women change during medical school? CMAJ 1999;160(3):357-361.

44. Risberg G, Hamberg K, Johansson EE. Gender awareness among physicians-the effect of specialty and gender. A study of teachers at a Swedish medical school. BMC Med Educ 2003;3:8.

45. Satterlee WG, Eggers RG, Grimes DA. Effective medical education: insights from the Cochrane Library. Obstet Gynecol Surv 2008;63(5):329-333.

46. Draugalis JR, Coons SJ, Plaza CM. Best practices for survey research reports: a synopsis for authors and reviewers. Am J Pharm Educ 2008;72(1):11.

47. Paice E, Heard S, Moss F. How important are role models in making good doctors? BMJ 2002; 325(7366):707-710.

48. Stern DT, Papadakis M. The developing physicianbecoming a professional. N Engl J Med 2006; 355(17):1794-1799.

49. Van der Vleuten CPM. The need for evidence in education. Dolmans DHJM, Scherpbier AJ, editors. Med Teach 2000;22(3),246-250.

\section{De auteurs:}

Drs. P.W. Dielissen is huisarts-onderzoeker.*

Dr. B.J.A.M. Bottema is huisarts en hoofd Vervolgopleiding tot Huisarts. *

Prof. dr. A.L.M. Lagro-Janssen is huisarts en hoogleraar Huisartsgeneeskunde en Seksespecifieke geneeskunde. * Dr. P. Verdonk is psycholoog en universitair docent Arbeid en Gezondheid, Faculteit HML, Afdeling Sociale Geneeskunde, Maastricht.

*Allen verbonden aan de afdeling UMC St Radboud, Eerstelijnsgeneeskunde, Nijmegen.

\section{Correspondentieadres:}

P.W Dielissen, huisarts, UMC St Radboud, VOHA 166, postbus 9101, 6500 HB Nijmegen. Tel: 024-3615300; e-mail:P.Dielissen@elg.umcn.nl

Belangenconflict: geen gemeld

Financiële ondersteuning: geen gemeld

\section{Summary}

Background: Gender matters in health care. General practitioners are increasingly expected to take account of contextual factors, including gender, and gender-related competencies have been developed for postgraduate training in family medicine. GP trainees should acquire these competencies during their training. This paper describes a course on gender-specific factors in family medicine and trainees' evaluations of it.

Methods: The course is designed for GP registrars and is delivered in several modules spread over the three-year training programme in family medicine. The modules emphasise interaction, application, and clinically integrated learning and teaching methods in peer groups. In 2005-2008, after completion of each module, GP registrars were asked to fill in a questionnaire consisting of items with 5-point Likert scales to assess the programme's methods and content. They were also asked to write two important learning experiences that had resulted from the programme.

Results: The programme consists of five 3-hour modules covering gender themes related to and frequently seen by GPS such as in doctor-patient communication, cardiovascular disease, and depression. GP registrars evaluated the course positively. The written learning experiences suggest that GP registrars became more aware of why attention to genderspecific information is relevant.

Conclusions: Gender-specific medical training has been successfully integrated into an existing postgraduate programme in family medicine. The modules and teaching methods are transferable to other postgraduate programmes in family medicine. The course evaluation shows a positive impact on GP registrars' awareness of gender as an important factor in family medicine. (Dielissen PW, Bottema BJAM, Verdonk P, Lagro-Janssen ALM. An integrated genderspecific course in the Nijmegen postgraduate training programme in family medicine: competencies, methods and evaluation. Netherlands Journal of Medical Education 2010(29);3:200-209.) 